\title{
Acute Myocardial Infarction Identified in a Peripheral Clinic and Treated with Urgent Surgical Revascularization: Door to Knife in Less than Three Hours
}

\author{
RD Rampersad, CK Toussaint, N Rahaman, GD Angelini
}

\section{INTRODUCTION}

According to the World Health Organization, coronary heart disease kills more people each year in high, middle and low income countries alike than any other disease. The 2012 Pan American report for Trinidad and Tobago showed a $51 \%$ raised risk for non-communicable lifestyle disease and the concomitant risk of cardiac disease in the 25-64-year age group with a reported increased rate of obesity, hypertension and diabetes (1).

The urgent management of the patient with acute coronary syndrome is dictated by the need to prevent irreversible damage and infarcted myocardium (2). The question of the advancement of technology and the availability of healthcare as it relate to service that is needed, cost of the service and the overall economical benefit, is forever being asked. Even though they are considered developing countries, Trinidad and Tobago and the wider Caribbean have kept up with the advancement of technology in early diagnosis and treatment of heart related problems. However, in Trinidad and Tobago where cardiovascular disease is reaching epidemic proportion, more work is required to educate the general public as well as providing a 24-hour integrated cardiac service. This will be possible only with a clear and committed service delivered as a joint effort between the private and public sectors (3).

Keywords: Bypass, cardiovascular surgery, myocardial infarction

\section{CASE REPORT}

A 56-year old male, with a past history of hypertension and dyslipidaemia, presented to a rural satellite cardiac clinic complaining of typical chest pain at rest. Of significance in his history, a stress echocardiogram performed one week prior to presentation was positive for ischaemia and showed hypokinesia in the mid septal and mid anteroseptal wall.

From: Caribbean Heart Care Medcorp, 18 Elizabeth Street, St Clair Medical Centre, St Clair, Port-of-Spain, Trinidad and Tobago.

Correspondence: Dr RD Rampersad, St Clair Medical Centre, Caribbean Heart Care Medcorp, 18 Elizabeth Street, St Clair, Port-of-Spain, Trinidad and Tobago. E-mail: rrampersad@hotmail.com
Upon review by the cardiologist, his electrocardiogram (ECG) showed ST depression 2-3 mm in the lateral leads. He was given aspirin $80 \mathrm{mg}$, clopidogrel $300 \mathrm{mg}$, nitroglycerine patch $0.4 \mathrm{mg} /$ hour and immediately transferred via ambulance to a private specialized centre.

The diagnosis on admission was of acute coronary syndrome, non-ST segment elevation myocardial infarction with positive troponin and within 20 minutes he was taken to the catheterization laboratory after informed consent was obtained for angiography plus possible percutaneous coronary intervention (PCI) or coronary artery bypass surgery.

Coronary angiogram showed a 95\% severe distal left main (LM) lesion, 70\% middle stenosis of the left anterior descending artery (LAD) and a 95\% proximal stenosis of first obtuse marginal (OM1) branch of the circumflex artery. His right coronary artery (RCA) was occluded proximally with collateral circulation from the LAD.

A decision was made jointly by the cardiologist and cardiothoracic surgery team to transfer the patient immediately for surgery due to his ongoing chest pain not relieved medically and ECG changes and the risk of sudden death from the severe LM stenosis. The patient underwent off pump coronary revascularization with a left internal mammary artery (LIMA) to the LAD and saphenous grafts to the posterior descending and OM1 arteries. The time that elapsed from diagnosis to start of the surgery was less than three hours.

On completion of the surgery, the patient was transferred to the intensive care unit in a haemodynamically stable condition and after an uneventful recovery was discharged home on the fourth postoperative day. At one year of followup, the patient was asymptomatic, with negative noninvasive ischaemic testing and optimal exercise capacity.

\section{DISCUSSION}

This case exemplifies the need for early detection, diagnosis and a readily available cardiac team to respond to a lifethreatening cardiac condition. The treatment of this patient was an excellent example of guidelines implementa-tion, where within the set time limits his acute ischaemia was addressed with coronary artery bypass graft surgery (CABG) when management by PCI was not feasible. 
Many patients are unaware of symptoms of cardiac pain or are reluctant to call for early medical help. Patients may be unaware of the emergency ambulance service numbers and rural hospitals are sometimes underequipped with emergency vehicles (4). Often, hospitals are understaffed and underequipped to properly meet the recommendations of American and European cardiology guidelines $(5,6)$ of door to ECG of 10 minutes and first medical contact (FMC) to needle of 30 minutes in the case of fibrinolysis or FMC to PCI of 90 minutes. In addition, the latter, in Trinidad and Tobago, is limited to private institutions and can only be accessed in the public sector at Eric Williams Medical Sciences Complex but not on a 24-hour basis. Coronary artery bypass grafting is available on an emergency basis only in the private sector (3).

There is urgent need for structured plans to address the critical issues of primary prevention and education of the population on a healthier lifestyle. Implementation of a structured framework is necessary so that the population can be aware of the available facilities in case of an acute coronary event. Institutional issues in medical efficiency and best use of available resources must be addressed.

Finally, in a country where cardiovascular disease is reaching epidemic proportion, a joint effort between the private and public sectors could be a most efficient option.

\section{REFERENCES}

1. Ministry of Health Trinidad and Tobago. Trinidad and Tobago chronic non-communicable disease risk factor survey (Pan American STEPS). Final report [Internet]; 2012 [rev 2014 Jan 1; cited 2014 Jan 20]. Available from: http://www.health.gov.tt/news/newsitem.aspx?id=394
2. Esposito G, Dellegrottaglie S, Chiariello M. The extent of irreversible myocardial damage and the potential for left ventricular repair after percutaneous coronary intervention. Am Heart J 2010; 160 (6 Suppl): S4-10.

3. Thomas C, Boodhoo L, Chacko M, Rampersad RD, Williams A, Ramoutar $\mathrm{P}$ et al. The cardiac catheterization lab: implementing best practice in Trinidad and Tobago. CMJ 2012; 74: 22-6.

4. Cooney DR, Wojcik S, Seth N, Vasisko C, Stimson K. Evaluation of ambulance offload delay at a university hospital emergency department. Int J Emerg Med 2013; 6: 15. DOI: 10.1186/1865-1380-6-15.

5. Task Force on the management of ST-segment elevation acute myocardial infarction of the European Society of Cardiology (ESC); Steg PG, James SK, Atar D, Badano LP, Blömstrom-Lundqvist C et al. ESC guidelines for the management of acute myocardial infarction in patients presenting with ST-segment elevation. Eur Heart J 2012; 33: 2569-619. DOI: 10.1093/eurheartj/ehs215. Epub 2012 Aug 24.

6. Antman EM, Anbe DT, Armstrong PW, Bates ER, Green LA, Hand M et al. ACC/AHA guidelines for the management of patients with STelevation myocardial infarction - executive summary: a report of the American College of Cardiology/American Heart Association Task Force on Practice Guidelines (Writing Committee to Revise the 1999 Guidelines for the Management of Patients with Acute Myocardial Infarction). Circulation 2004; 110: 588-636.

Submitted 04 Feb 2014

Accepted 12 Feb 2014

Published 15 Apr 2014

Online: http://myspot.mona.uwi.edu/wimjopen/article/56

(C) Rampersad et al 2014.

This is an open access article made freely available under Creative Commons Attribution 4.0 International (CC BY 4.0). Users are free to share, copy and adapt this work as long as the copyright holder (author) is appropriately and correctly credited. See http://creativecom mons.org/licences/by/4.0/deed.en_us for more information. 